Review Article

\title{
DNA lesions and repair in trypanosomatids infection
}

\author{
Bruno M. Repolês ${ }^{1}$, Carlos Renato Machado ${ }^{1}$ and Pilar T. V. Florentino ${ }^{2}$ (D) \\ ${ }^{1}$ Universidade Federal de Minas Gerais, Departamento de Bioquímica e Imunologia, Belo Horizonte MG, \\ Brazil. \\ ${ }^{2}$ Universidade de São Paulo, Departamento de Microbiologia, São Paulo, SP, Brazil.
}

\begin{abstract}
Pathological processes such as bacterial, viral and parasitic infections can generate a plethora of responses such as, but not restricted to, oxidative stress that can be harmful to the host and the pathogen. This stress occurs when there is an imbalance between reactive oxygen species produced and antioxidant factors produced in response to the infection. This imbalance can lead to DNA lesions in both infected cells as well as in the pathogen. The effects of the host response on the parasite lead to several kinds of DNA damage, causing alterations in the parasite's metabolism; the reaction and sensitivity of the parasite to these responses are related to the DNA metabolism and life cycle of each parasite. The present review will discuss the survival strategies developed by host cells and Trypanosoma cruzi, focusing on the DNA repair mechanisms of these organisms throughout infection including the relationship between DNA damage, stress response features, and the unique characteristics of these diseases.
\end{abstract}

Keywords: Trypanosoma cruzi, reactive oxygen species, DNA repair.

Received: May 20, 2019; Accepted: October 21, 2019.

\section{Introduction}

The Kinetoplastida order comprises several Protozoa that can be parasitic or not. They share some unique characteristics, most remarkably the presence of a single and unique organelle called a kinetoplast. In this order, three of the major parasitic pathogens of medical importance are part of the Trypanosomatid family: Leishmania spp. (the etiological agent of the various forms of leishmaniasis), Trypanosoma brucei (the causative agent of African sleep sickness) and Trypanosoma cruzi (the etiological agent of Chagas disease, also named American trypanosomiasis). All these organisms have a heteroxenous life cycle, needing two hosts one invertebrate and another vertebrate; therefore, they present more than one parasitic form (Chagas, 1909; Rassi et al., 2010; Cantey et al., 2012; Centers for Disease and Control Prevention, 2018). Generally, diseases caused by trypanosomatids are zoonotic, i.e., they have animals as a natural reservoir and infection in humans is dependent on the maintenance of these reservoirs to sustain endemicity. Although T. cruzi and T. brucei are in the same genus, they have a distinct life cycle. Information about the $T$. cruzi life cycle is summarized in Box 1.

Several reviews have already addressed the particularities of how the trypanosomatids escape from the immune system (Oladiran and Belosevic, 2012; Geiger et al., 2016;

Send correspondence to Pilar T.V. Florentino. Universidade de São Paulo, Departamento de Microbiologia, Av. Lineu Prestes 1374, Butantã, 05508-900, São Paulo, SP, Brazil. E-mail: pilar.veras@gmail.com
Weatherly et al., 2016). Although T. brucei has recently been reported in the adipocytes of mice (Trindade et al., 2016), this parasite is present in a bloodstream-specific form in mammals and, therefore, has to deal with the attack of the host's immune system. To be able to escape from the immune system, T. bruce $i$ has an extensive repertoire of variant surface glycoproteins (VSGs) that must be constantly exchanged (Taylor and Rudenko, 2006); this indicates a role for homologous recombination in the DNA metabolism of

\section{Box 1 - Trypanosoma cruzi life cycle}

Trypanosoma cruzi is a heteroxenous parasite with a digenetic life cycle that involves two hosts: an invertebrate one, usually an insect of the order Triatomina and a vertebrate host. In each of these hosts and stages of development, the parasite assumes a different morphology. T. cruzi infection can occur by transfusion using contaminated blood, oral infection via contaminated food, or by direct infection by the insect vector. In a typical $T$. cruzi life cycle, the trypomastigote form of the parasite is deposited in the feces of the insect vector. The infection occurs when the feces come into contact with any mucosal tissue or the bloodstream. After that, the parasite is able to infect several types of cells, including macrophages, cardiomiocytes, adipocytes, epithelial cells, and neurons. During infection, $T$. cruzi trypomastigotes form a parasitophorous vacuole inside the host cell, and then escape from this vacuole into the cytoplasm. The parasite then differentiates into the replicative amastigote cell, further replicates, and transforms again into the trypomastigote form. Finally, the host cell bursts and releases new parasites to continue the infection cycle. When another insect vector feeds on blood containing trypomastigotes parasites, $T$. cruzi then reaches the intestinal tract of this insect. In the insect gut, the parasite differentiates into the replicative epimastigote form, replicates again, then differentiates into the trypomastigote, which then undergoes another infection cycle within the mammalian host. 
this parasite (McCulloch and Barry, 1999; Glover et al., 2008; Horn and McCulloch, 2010).

For T. cruzi, the first barrier is immune system recognition in the bloodstream. In the mammalian host, bloodstream T. cruzi has to combat the host's complement system, and therefore, the parasite expresses several proteins that interfere with the complement system. One of those proteins is T-DAF (trypomastigote decay-accelerating-factor), a protein capable of blocking the assembly of the $\mathrm{C} 3$ convertases from the complement system. The parasite also expresses several complement regulatory proteins (CRPs) and calreticulin (CRT) that also interfere with the complement system (Norris et al., 1991; Tambourgi et al., 1993; Cestari et al., 2009; Ramírez et al., 2011). The parasite also possesses trans-sialidases proteins that interfere with host lymphocytes as well as sialylated mucins and cruzipain that actively protect the parasite against antibodies from the host immune system (Berasain et al., 2003; Giorgi and De Lederkremer, 2011; Alvarez et al., 2012). The intracellular amastigote form requires an extensive repertoire of oxidative response proteins to cope with the new intracellular environment. During the intracellular phase, the host cell activates several oxidases in the parasitophorous vacuole, creating an oxidative burst via the generation of several reactive oxygen species (ROS) that can attack the parasite. The parasite's response repertoire must also include DNA damage response proteins to oxidative stress (Passos-Silva et al., 2010; van Loon et al., 2010; Alvarez et al., 2011; Genois et al., 2014; Machado-Silva et al., 2016).

During Chagas disease, T. cruzi has an intracellular form that must also resist the oxidative insult caused by the host cell. The primary response against the parasite is the oxidative burst caused during the infection, which consists mainly of superoxide anions and ROS (Müller et al., 2003; Alvarez et al., 2004; Piacenza et al., 2009a,b). This insult is the most deleterious for the parasite and, therefore, the most studied. These pathological processes that generate oxidative stress can be very harmful to the individual and pathogen (Nathan and Shiloh, 2002). Stress occurs when there is an unbalance between reactive oxygen species (ROS: hydroxyl radical, nitric oxide, superoxide, hydrogen peroxide, hypochlorous acid, and singlet oxygen) and antioxidant species (superoxide dismutase, glutathione reductase, glutathione, $\alpha$-tocopherol, and ascorbic acid). The main reactive oxygen species (ROS) targets include DNA, RNA, lipids, proteins, and carbohydrates. However, DNA lesions result in cell cycle arrest and death, as it is the molecule responsible for genetic information of all cells from a single organism (Berra et al., 2006). Beyond oxidative stress, the importance of preserving genomic integrity is evident by the fact that DNA repair mechanisms are present in all organisms, as we have the description of DNA repair proteins and enzymes from bacteria to higher eukaryotes (Hoeijmakers, 2001; DiRuggiero and Robb, 2004; Cagney et al., 2006).

During the cell cycle, DNA repair pathways ensure the fidelity of the DNA information transferred (Friedberg, 2008). The complexity of these processes becomes clear when we consider that, for any eukaryotic cell, there are numerous sources of DNA damage, which need to be detected and repaired (Hoeijmakers, 2001; Hakem, 2008; Tubbs and Nussenzweig, 2017). DNA damage response leads to different cellular effects, such as cell cycle arrest, activation of distinct signaling pathways, and modulation of the DNA metabolism pathways (Hoeijmakers, 2001; Marnett and Plastaras, 2001; Harper and Elledge, 2007; Lord and Ashworth, 2012; Imlay, 2013). Therefore, although the DNA damage response is divided into pathways, the alterations in the cell comprise other metabolic pathways that are not so logical at first glance.

In this review, we will discuss what is already known about DNA metabolism and repair during T. cruzi infection and how these processes affect host cell metabolism. Thus, we will explore how DNA metabolism may be related to alterations in cellular metabolism and how these changes impact the pathogenesis of Chagas disease.

\section{Metabolic effects of oxidative stress in T. cruzi}

As an obligate intracellular parasite, T. cruzi has to combat oxidative stress generated by the host cell. The primary host response against the parasite is the oxidative burst caused by the infection, which consists mainly of superoxide anions and ROS (Müller et al., 2003; Alvarez et al., 2004; Piacenza et al., 2009a,b).

With such specific environmental insults during the parasite life cycle, T. cruzi reacts with several metabolic responses to attempt to prevent the damage caused by ROS. A significant protein in this response is a parasite-specific superoxide dismutase (SOD), a protein already reported to protect the parasite from intracellular-generated ROS by macrophages (Mateo et al., 2008; Martinez et al., 2018). SOD is an enzyme that catalyzes the dismutation of superoxide $\left(\mathrm{O}_{2}{ }^{-}\right)$into hydrogen peroxide $\left(\mathrm{H}_{2} \mathrm{O}_{2}\right)$. In $T$. cruzi the SOD enzyme does not possess a copper/zinc or manganese mechanism; T. cruzi SODs are present in four iron-dependent versions of SOD (FeSOD) A, B1, B2, and C. It has been demonstrated that the overexpression of FeSOD C within the mitochondria was able to improve the resistance of the pathogen to ROS generated by the presence of bovine serum (Boveris and Stoppani, 1977; Piacenza et al., 2007).

Contrary to most organisms, trypanosomatid glutathione is a tiny fraction of the pool of enzymes. Most eukaryotes rely on a system composed of glutathione and glutathione reductase in a system that uses glutathione as reductive power to neutralize oxidative molecules, in a reaction catalyzed by glutathione reductase (Krauth-Siegel et al., 2003; Müller et al., 2003). In these parasites, the trypanothione system is responsible for protecting those organisms from oxidative insult (Fairlamb et al., 1985; Fairlamb and Cerami, 1992; Meziane-Cherif et al., 1994). This protein is homologous to the human glutathione reductase, an enzyme capable of performing the reduction of glutathione disulfide into the sulfhydryl form glutathione (Fairlamb et al., 1985; Piacenza et al., 2009b). Although this protein is essential to the response of $T$. cruzi to oxidative assault, there is 
still some debate regarding its subcellular localization in the parasite, as the presence of trypanothione reductase was reported in the parasite's kinetoplast (Meziane-Cherif et al., 1994), yet fractionation studies showed that this localization might be more diffuse than previously thought (Wilkinson et al., 2002).

One of the main classes of proteins involved in the cytosolic response against ROS in $T$. cruzi is the family of peroxiredoxins. Two of these well-characterized proteins in T. cruzi are the mitochondrial and cytosolic tryparedoxin perioxidase proteins (TcMPx and TcCPx, respectively) (Piacenza et al., 2009b). Overexpression of these proteins can confer resistance to peroxynitrite. Expression of both proteins differs among the T. cruzi forms, as it is higher in metacyclic trypomastigotes than in epimastigotes (Piacenza et al., 2009b). The existence of several proteins to deal with oxidative stress indicates how important the oxidative response is for the parasite.

\section{DNA repair and response to oxidative stress in T. cruzi}

The oxidative stress that surpasses the first line of defense of the parasite, composed by the aforementioned antioxidant proteins, constitutes a potential source of damage to the intracellular components of the organism. One primary target of ROS in living organisms is DNA. Among many effects, oxidative stress can generate apurinic/apyrimidinic (AP) sites and base modifications, one of the most common of which is the modified base 7,8-dihydro-8-oxoguanine also known as 8-oxoguanine (8-oxodG) (Kanvah et al., 2010). Further studies of the response of $T$. cruzi to the damage caused by 8-oxoguanine in each forms of the parasite are necessary since one of the two crucial drugs used against this parasite, benznidazole (BZN), is able to induce oxidative stress primarily by targeting guanine in the nucleotide pool of the parasite (Rajão et al., 2014).

8-oxoguanine can be generated directly on doublestranded DNA, but also by the oxidation of the guanine present on the cell nucleotide pool (Mahon et al., 2007; Aguiar et $a l ., 2013)$. This modified base mutagenicity is due to its ability to cause transversions when not corrected by the DNA repair system since replicative polymerases can incorporate cytosine or adenine in opposition to 8-oxodG. Therefore, this modified base can be incorporated in opposition to an adenine, causing the transversion AT to CG (Cadet et al., 2003; Barzilai and Yamamoto, 2004; van Loon et al., 2010).

There are several pieces of evidence indicating that DNA repair factors are not restricted to one pathway, but instead can be involved with the regulation and control of multiple DNA repair pathways (Nemzow et al., 2015). Although the response against oxidative insult is very complex and involves multiple metabolic alterations (Pascucci et al., 2011; Melis et al., 2013), the primary pathway involved in DNA repair is base excision repair (BER) (Hoeijmakers, 2001; Barzilai and Yamamoto, 2004). In general terms, the BER pathway consists of several DNA glycosylases, each one specifically recognizing one type of modified base. These proteins can flip the modified base out of the DNA strand and cleave it from the sugar-phosphate backbone. This cleavage will generate an AP site, cleaned by some endonucleases; sometimes this hydrolysis occurs spontaneously (Meadows et al., 2003). From this point forward the pathway can take two directions: the short-patch BER, in which a polymerase, such as polymerase $\beta$ (Pol $\beta)$, performs a single nucleotide gap fill on the damage site, or the longpatch BER, in which, in coordination with proliferating cell nuclear antigen (PCNA), polymerization of a more substantial portion of the DNA and displacement of the damaged single-strand occurs, generating a DNA flap. Next, the DNA flap is removed by flap endonuclease 1 (FEN1), and the DNA nick is closed by a specific DNA ligase (Hoeijmakers, 2001; David et al., 2010; Wallace 2014).

The oxidative response is one of the main fields of study for T. cruzi and proteins involved in all steps of both BER pathways have already been described (Passos-Silva et al., 2010; Genois et al., 2014). One significant protein already reported in $T$. cruzi is the homolog for AP endonuclease, the enzyme responsible for cleaning AP sites from the genome, thereby preventing cytotoxic effects during replication. Two AP endonuclease (APE) homologs were reported: TcAPE1 (orthologous to Homo sapiens APE1) and TcAP2 (orthologous to Homo sapiens APE 2 and Schizosaccharomyces pombe Apn2p) (Sepúlveda et al., 2014). These proteins were identified in replicative forms of the parasite, demonstrating the importance of their expression for accurate DNA replication. The overexpression of these proteins confers higher resistance to oxidative stress, especially in a continuous and persistent oxidative environment, when compared with wildtype (WT) strains, thus demonstrating how essential DNA repair is to the survival of the parasite in the face of oxidative attacks (Sepúlveda et al., 2014). Although there is much investigation into the epimastigote form, there is lack information regarding the influence of these genes in the amastigote form of the parasite.

One piece of evidence for the presence of the shortpatch BER in T. cruzi is the observation that the parasite can cope with uracil by using the protein Tc-uracil DNA glycosylase (TcUNG) that removes misincorporated uracil in single-strand DNA in front of cytosine and adenine substrates (Peña-Diaz et al., 2004). Evidence of a canonical BER pathway was provided by a study that reported that the function of TcUNG is increased in vitro in the presence of AP endonuclease (Farez-Vidal, 2001), suggesting that these two proteins act on the same pathway. The long-patch repair pathway also seems to be present in all forms of $T$. cruzi since a recent paper described the presence of Tc-Flap endonuclease 1 (TcFEN1), a homolog of human FEN1. In this work, TcFEN1 increased parasite resistance to oxidative stress when overexpressed; this protein deals with DNA intermediates containing a 5' flap, showing a protein specific to LP-BER in this parasite (Ponce et al., 2017).

Among DNA modifications caused by oxidative stress, the most prevalent is the generation of 8-oxodG. Nevertheless, several groups of organisms have a BER 
subpathway, the GO system, which can handle damage caused by 8-oxodG (Michaels and Miller, 1992; Nash et al., 1996; Slupska et al., 1996; Radicella et al., 1997; Kuipers et al., 2000; Barzilai and Yamamoto, 2004; Hwang et al., 2014; Boiteux et al., 2017). Three proteins from the GO system are significant in prokaryotic cells: MutM (also named FPG), repairs 8-oxodG already misincorporated to cytosine. MutY, removes an adenine misincorporated in front of 8oxodG in double-stranded DNA, and MutT hydrolyzes 8-oxod-GTP into its monophosphate form, preventing its misincorporation into the DNA molecule by DNA polymerase (Michaels and Miller, 1992).

For T. cruzi, all three proteins of the GO system have been characterized (Furtado et al., 2012; Aguiar et al., 2013; Kunrath-Lima et al., 2017). Initially, only TcOGG1 (FPG homolog for T. cruzi) and TcMYH (MutY homolog for $T$. cruzi) were identified as part of the T. cruzi CL Brener strain genome deposited in TritrypDB (El-Sayed et al., 2005). Heterogeneous expression of TcOGG1 in Oggl mutants of Saccharomyces cerevisiae could complement the deficient phenotype of the yeast. In T. cruzi, OGG1 is located on nuclear and kinetoplast DNA. The protein was also functional in both organelles as overexpression sensitized the parasite to oxidative stress and led to lower rates of 8-oxodG (Furtado et al., 2012). A similar result was observed for TcMYH, which is found in nuclear and kinetoplast DNA; overexpression of this protein led to increased sensitivity of the modified strain (Kunrath-Lima et al., 2017). In addition, the parasite possesses a functional MutT homolog, which can complement MutT-deficient E. coli; overexpression of this protein increased resistance, decreasing parasite DNA damage (Aguiar et al., 2013). The difference observed after overexpression of each protein can be explained by their function. MutY and OGG1 are proteins that act directly on the lesion already incorporated into the DNA strand, generating AP sites for the BER pathway to repair; however, MutT acts before incorporation, by removing the modified base as a substrate for the DNA polymerase (Michaels and Miller, 1992) and their homologs may act in the same way in T. cruzi. Thus, TcMYH and TcOGG1 overexpression may cause an imbalance in the DNA repair system of these modified strains, generating more AP sites than the parasite has the ability to efficiently repair. In fact, strains overexpressing TcMYH accumulate more AP sites after treatment with $\mathrm{H}_{2} \mathrm{O}_{2}$ and have a higher and earlier peak of AP sites in the genome as compared to the WT strain (Kunrath-Lima et al., 2017). By using these mutants it was demonstrated that overexpression of TcMTH, but not TcMYH or TcOGG1, leads to higher resistance to BZN (Rajão et al., 2014). This result indicates that BZN has a preference for action on the nucleotide pool and also targets parasite DNA; thus this is a direct link between DNA metabolism and Chagas disease treatment.

Regarding infection capability, overexpression of TcMTH increased both parasitemia and the number of amastigotes per cell in vitro as compared to the WT strain (Aguiar et al., 2013; Goes et al., 2016). An intriguing finding was that, after pre-treatment with a sublethal dose of $\mathrm{H}_{2} \mathrm{O}_{2}$, the number of intracellular parasites per cell after infection was higher when the authors compared the non-treated overexpressing cells with the pre-treated overexpressing cells (Aguiar et al., 2013). Also, when an experiment was performed using Phox KO macrophage (i.e., mice deficient in the gp91 ${ }^{\text {phox }}$ subunit of the NADPH oxidase), which impairs ROS production post-infection, the authors found that the parasitemia in modified macrophages was lower than in control cells (Goes et al., 2016). These results are in agreement with previous works that had described oxidative stress as a factor that enhances the parasite infection (Paiva et al., 2012; Paiva and Bozza, 2014), but the exact signal that these ROS give remains unclear.

The investigation into the importance of the response to ROS for T. cruzi was based on the finding that the parasite lacks, in its annotated genome, the sequence for the catalase gene (Boveris et al., 1980; El-Sayed et al., 2005; Freire et $a l ., 2017)$. Catalase is an antioxidant enzyme found in nearly all aerobic organisms. It performs the decomposition of hydrogen peroxide into water and oxygen (Chelikani et al., 2004), two molecules that are not harmful to most organisms. The lack of such an essential gene was unexpected given the importance for $T$. cruzi to fight oxidative stress, and given the central role catalase plays in oxidative defense in several organisms (Chelikani et al., 2004). The most exciting finding was that the heterologous expression of the catalase gene from E. coli (KatE) in T. cruzi increased parasite resistance to hydrogen peroxide. However, when the cells were pre-treated with a sub-lethal dose of $\mathrm{H}_{2} \mathrm{O}_{2}$, there was no difference in survival as compared with KatE in WT strains (Freire et al., 2017). These results suggest that the pre-treatment can induce a cellular adaptation in WT strains of T. cruzi, a condition that is abrogated with the expression of the heterologous KatE gene. T. cruzi modified with KatE also exhibited higher parasitemia, infection index, and midgut proliferation in the invertebrate host when compared to WT cells (Freire et al., 2017). Taken together, these results help illustrate a scenario in which ROS provides a signal for T. cruzi proliferation in cells, as observed in other works (Paiva et al., 2012) and that, the abolishment of this signal caused by KatE, which degrades $\mathrm{H}_{2} \mathrm{O}_{2}$ into two nonsignaling molecules, can alter the parasitic response to this stress and allow T. cruzi to benefit from oxidative stress to replicate in their hosts.

The parasite response to the insults caused by the host cell is, therefore, very complex and is summarized in Figure 1. Oxidative stress is related to several kinds of damage (Imlay, 2013), but the investigation into the relevant parasitic machinery to combat the resulting DNA damage demonstrates that repair and signaling machinery is essential for the parasite to sustain infection both in vitro and in vivo. However, the exact role of this signal in amastigotes is not yet clear. The majority of experiments were performed on the epimastigote and trypomastigote forms of the parasite, and investigation of the particularities of the amastigote form remains an interesting field of study. 


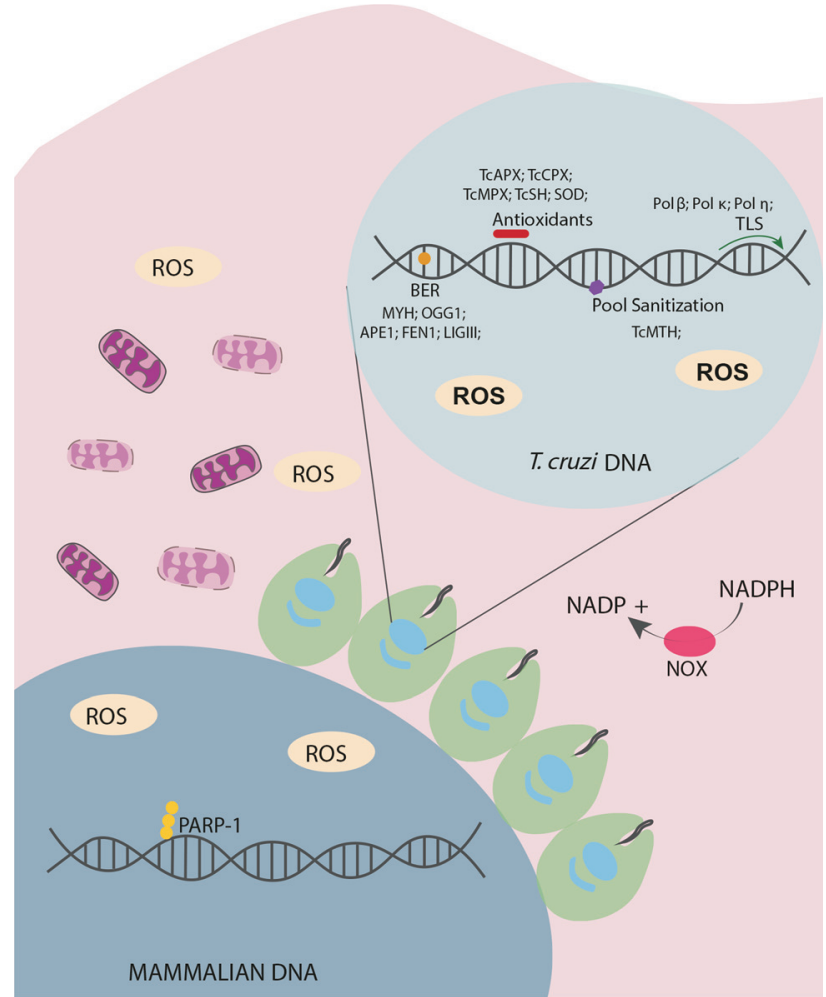

Figure 1 - Oxidative stress in parasite-host interaction in T. cruzi. After infection, the parasite faces oxidative stress induced by the host cell. Parasites have several defense mechanisms to prevent damage to the nuclear and kinetoplast DNA. The first line of defense is composed of several antioxidants proteins; of these, TcAPX, TcCPX, TcMPX, TcSH, and SOD proteins are the best characterized. ROS that escape from the antioxidant system can cause DNA damage when they encounter parasite DNA molecules (8-oxoG is the most common modification that arises from this stress). To prevent the deleterious effects, the parasite has a specific BER subsystem (GO System), that directly interacts with the modified base within the genome (TcOGG1) or any mispair with this base (TcMYH). The BER repair system has been extensively studied in the parasite and proteins from all steps of this repair pathway have been characterized. The last component of the GO system, the TcMTH protein, has also been identified in T. cruzi. If any damage persists in the parasite's nuclear or mitochondrial genome, translesion polymerases have also been identified, demonstrating that the parasite has means to survive massive amounts of oxidative stress.

\section{Mitochondrial DNA damage response}

Although the response to oxidative stress is a significant area of research in $T$. cruzi, since the oxidative burst is the major insult the parasite faces during infection, little is known regarding parasitic mitochondrial ROS generation and mitochondrial DNA repair. It has long been reported that some DNA repair pathways are absent from the mitochondria. For over thirty years, there have been reports of BER proteins in the mitochondria (Anderson and Friedberg, 1980; Pettepher et al., 1991). Repair of double-strand breaks has already been described in some organisms such as fungi and plants (Manchekar et al., 2006; Morel et al., 2008; Mileshina et al., 2011), but mammalian cells possess only a basic recombination machinery in the mitochondria (Thyagarajan et al., 1996). Mitochondrial recombination events are rare, and some of the necessary components are involved in other DNA metabolic functions (Minczuk et al., 2011). Mismatch resolution in mitochondrial DNA has only been recently described in some human cell lines and some other mammals (Mason et al., 2003; Souza-Pinto et al., 2009). Interestingly, general MMR nuclear proteins are not located in mitochondria, suggesting that different pathways occur in this organelle (Kazak et al., 2012). Further details about specific pathways present in mitochondria of higher eukaryotes have already been reviewed in other works (Shokolenko et al., 2011;Kazak et al., 2012; Alexeyev et al., 2013). T. cruzi and other trypanosomatids possess a single and modified mitochondria, allowing their use as great model organisms to study mitochondrial DNA repair. T. cruzi has been reported to be able to repair both the nuclear and mitochondrial DNA damaged by oxidative stress, although the level of kDNA damage is lower and more consistent than in the nuclear DNA. In addition, DNA repair in the kinetoplast does not eliminate all damage, as detected by a qPCR assay (Furtado et al., 2012).

The main type of DNA damage generated by oxidative stress is the 8-oxodG base modification, which can be repaired by the GO system. In the T. cruzi GO system, two proteins colocalize with kDNA. Although TcOGG1 is generally thought to be localized within the nucleus, it was also identified in the kDNA T. cruzi. In addition, mitochondrial 8oxodG levels were reduced in TcOGG1 overexpressing strains when compared to the control strain (Furtado et al., 2012). TcMYH was also co-localized in the kinetoplast of $T$. cruzi, although the localization demonstrated that the protein was also found in the parasite's nucleus. Overexpression of this protein caused a small elevation in the number mtDNA damage sites, as measured in mitochondria 30 minutes after the damage was induced and sensitized the cells to treatment with a specific mitochondrial stress agent (Kunrath-Lima et al., 2017).

During the resolution of oxidative damage by BER, one pathway involves the insertion of the correct nucleotide into the 3'-OH of the AP site previously generated, followed by the excision of the remaining sugar-phosphate bone (DRP-lyase activity), a process that can be catalyzed by DNA polymerase $\beta$ (Pol $\beta$ ) in some organisms (Allinson et al., 2001). In T. cruzi, Pol $\beta$ is present and is also able to perform these activities (Lopes et al., 2008; Schamber-Reis et $a l ., 2012)$. It was demonstrated that this protein can deal with oxidative lesions in the kinetoplast and that its localization is dependent on the cell cycle. During oxidative stress, the protein translocates into the antipodal sites of the kinetoplast (Schamber-Reis et al., 2012). Pol $\beta$ PAK, a homolog of Pol $\beta$ that contains a domain rich in proline, alanine, and lysine, has also been characterized in T. cruzi (Lopes et al., 2008). Pol $\beta$ PAK has a strict localization in the kDNA of T. cruzi and also possesses DRP-lyase activity. However, unlike Pol $\beta$, only Pol $\beta$ PAK is capable of performing a bypass of 8-oxodG (Lopes et al., 2008).

DNA polymerase kappa was also implicated in kDNA metabolism in T. cruzi (Rajão et al., 2009). Although the par- 
asite possesses more than one sequence of DNA polymerase kappa, one of the copies possesses a mitochondrial localization signal and specific kinetoplast localization. Like polymerase $\beta$ and $\beta$-PAK, DNA polymerase kappa can bypass 8 -oxodG damage, but can also replicate an intermediate recombination structure in vitro that mimics the D-loop (Rajão et al., 2009). Overexpression of these three polymerases increases parasite survival against BZN (Rajão et al., 2014), another direct link between DNA metabolism and Chagas disease treatment. It is worth noting that only DNA polymerase kappa (Rajão et al., 2009), TcOGG1 (Furtado et al., 2012), and TcMYH (Kunrath-Lima et al., 2017) possess a predicted mitochondrial localization signal; also, some kinetoplast associated proteins have no mitochondrial localization prediction, even though they are located in the organelle (Souza et al., 2010). Some other proteins, such as Rad51 can also be localized to the mitochondria, as seen by by immunofluorescence experiments, although they are also not predicted to be present in this organelle (Cerqueira et al., 2017), suggesting that the exportation of proteins to the mitochondria of $T$. cruzi still needs further study.

These data contribute to a scenario in which T. cruzi possesses, on the kinetoplast, proteins from all steps of the BER pathway, suggesting that the parasite can repair oxidative damages on the kDNA. Although the decrease in the number of lesions in the mitochondrial DNA observed in WT cells by qPCR is not significant (Furtado et al., 2012), the increase in the number of lesions on the kDNA caused by the overexpression of TcMYH (Kunrath-Lima et al., 2017) demonstrates that the kinetoplast does possess proteins for combating oxidative damage within this organelle. The quantification of DNA damage from other sources and repaired by other DNA repair pathways remain to be investigated.

\section{Chronic Chagas disease and DNA metabolism}

A remarkable characteristic of Chagas disease is the heterogeneity of its clinical manifestations. Immediately after the infection, patients initiate an acute phase of the disease that can last from 4-8 weeks and is, in most cases, asymptomatic (Prata, 2001; Pérez-Molina and Molina, 2018). Symptomatic acute phase patients can present symptoms like fever, inflammation at the location of infection, and unilateral palpebral edema (a clinical condition called Romaña sign). In severe cases, the acute phase can lead to acute myocarditis, meningoencephalitis, and pericardial effusion (Laranja et al., 1956; Teixeira et al., 2006; Pinto et al., 2008; Pereira and Navarro, 2013). However, the disease usually persists in an asymptomatic form and enters a chronic stage, which is characterized by low parasitemia (Pereira and Navarro, 2013). Only $30 \%$ to $40 \%$ of these patients develop cardiomyopathy, megaesophagus, or megacolon (Prata, 2001; Rassi et al., 2010; Pérez-Molina and Molina, 2018). It has been long known that treatment with BZN and nifurtimox (NX) provides a high cure rate when given during the acute phase (Bahia-Oliveira et al., 2000), but this treatment is 4 to 16 times less effective during the chronic phase
(Cançado, 2002). In this context, one of the biggest questions regarding Chagas disease is why the parasite can persist in such a long period of dormancy, in which the host exhibits low levels of parasitemia, lasting for years, and the parasite becomes resistant to treatment.

Recently, an interesting report revealed that during cellular infection the parasite develops a non-proliferating intracellular amastigote form (Sánchez-Valdéz et al., 2018). By using a cell division tracker and the 5-ethynyl-2'-deoxyuridine (EdU) thymidine analog, the authors were able to demonstrate that, although the BZN treatment is effective in reducing the number of trypomastigotes during the acute phase, there are still some amastigotes in dormancy and in a non-replicative state. Remarkably, the authors observed that, in vivo and in situ, even a single dormant amastigote cell can resume infection after this latency period, where the cells are dormant and in a non-replicative state (Sánchez-Valdéz et al., 2018). When those cells were challenged with BZN, those dormant amastigotes were resistant to treatment (Sánchez-Valdéz et al., 2018). Although it is not clear if BZN causes this dormancy, or if the parasite is already dormant and the treatment is unable to affect it since, as stated previously, BZN causes oxidation mainly on the parasite nucleotide pool (Rajão et al., 2014).

A state that resembles dormancy has already been previously reported for T. cruzi in epimastigote cultures under laboratory conditions. After exposure to high doses of gamma irradiation (i.e. $500 \mathrm{~Gy}$ ), epimastigotes enter a non-replicative state for a period of time that could be as long as 10 days (Regis-da-Silva et al., 2006; Alves et al., 2018; Silva et al., 2018), although parasite DNA is repaired during the first 48 hours after the damaging insult (Regis-da-Silva et al., 2006). This growth impairment was coincident with an arrest in S/G2 phase, which was diminished by the time of growth resumption (Garcia et al., 2016), indicating that those cells were not replicating. It has also been shown that resumption of parasite DNA repair and growth are dependent on Rad51 levels (Regis-da-Silva et al., 2006; Silva et al., 2018). Rad51 seems to be related to specific kinds of replicative stress, being necessary for the response to methyl methanesulfonate (MMS), an alkylating agent capable of causing stalled replication forks; however, RAD51 is not recruited in response to replicative stress caused by hydroxyurea (Silva et al., 2018). The relationship between those two dormant states needs to be investigated as it is not yet clear if they represent correlated events. Therefore, the control of replication and dormancy could be essential for $T$. cruzi survival.

It has recently been reported that in Chagas disease, dormancy is a mechanism by which $T$. cruzi can resist treatment with BZN, as demonstrated in both during in vivo and in vitro systems (Sánchez-Valdéz et al., 2018). This dormancy can be replicated in the laboratory by causing DNA damage and replication stress (Regis-da-Silva et al., 2006; Cerqueira et al., 2017; Alves et al., 2018; Silva et al., 2018). Furthermore, it was recently demonstrated that different $T$. cruzi discrete typing units (DTUs), clusters of parasites 
based on biogeographical data, sequencing, and similarity among strains, exchange genetic information (Alves et al., 2018), but the relationship between these phenomena and the differential virulence observed among these clusters has not yet been explored.

As with the discovery of the mechanism of BZN resistance (Rajão et al., 2014), researchers have demonstrated a direct interplay between DNA metabolism and repair during Chagas disease development. It will be of interest to determine how the DNA damage response can alter the parasite metabolism in a broader sense. Although the kinetics of some DNA repair pathways were previously elucidated, much more investigation is needed on the sensing and signaling to the oxidative environment and their related responses.

\section{Effects of oxidative stress induced by $T$. cruzi in the host cell}

The intracellular component of the T. cruzi life cycle begins with metacyclic or bloodstream trypomastigotes actively invading a host cell by disrupting the host cell membrane, stimulating cytosolic $\mathrm{Ca}^{2+}$ influx (Moreno, 2004; Tardieux, 2004). This event leads to several changes in the host cell, including mitochondrial membrane permeabilization and the induction of high levels of cytosolic ROS, which can signal apoptosis (Kroemer et al., 2007; Giorgi et al., 2012; Webster, 2012). The imbalance in ROS and antioxidant barriers has been described in many pathogen infections (Piacenza et al., 2019). During T. cruzi infection, NADP oxidase (NOX) 2 was reported to be present in the plasma membrane of macrophages (Cardoni et al., 1997). In addition, high levels of superoxide $\left(\mathrm{O}_{2}{ }^{-}\right)$and nitric oxide were released approximately 60-90 min after infection (Muñoz-Fernández et al., 1992; Alvarez et al., 2004). ROS generated in the intraphagosomal space is likely to have microbicidal effects on $T$. cruzi, which were reversed when T. cruzi cytosolic tryparedoxin was overexpressed. Higher levels of parasite survival after infection were observed. In addition, membrane potential loss from host cell mitochondria was observed after parasite cardiomyocyte infection. At $48 \mathrm{~h}$ post-infection, increased levels of cytosolic $\mathrm{O}_{2}{ }^{-}$were observed, even when ROS producing enzymes from host cells were pharmacologically inhibited (Gupta et al., 2009). The relationships between infection and oxidative stress are reviewed elsewhere (Gupta et al., 2011; Paiva et al., 2018).

As mentioned above, ROS produced by the host cell have a microbicidal effect on $T$. cruzi in the host cell environment (Muñoz-Fernandez et al., 1992; Alvarez et al., 2004). Recently, it was proposed that T. cruzi utilize their response to oxidative stress to survive inside the host cell cytosol. Briefly, macrophages and mice treated with cobalt protoporphyrin (CoPP), an antioxidant that induces heme oxygenase (HO-1) expression through nuclear erythroid factor-2 (NRF-2), reduced parasite growth. Paiva et al. (2012) observed that the treatment of infected cells with several antioxidants (apocynin, superoxide dismutase, N-acetyl-Lcysteine, resveratrol) reduces parasite burden. Also, there is evidence that BZN, the drug used to treat Chagas disease, stimulates NRF2 (Rigalli et al., 2016). Conversely, when they treated infected cells with a respiratory burst inducer, phorbol 12-myristate 13-acetate (PMA) and $\mathrm{H}_{2} \mathrm{O}_{2}$, parasite burden increased significantly. These results raise an important question: could oxidative stress not only benefit the parasite but also prejudice host cell? Thus, how the oxidative stress induced by T. cruzi could harm the host cell is not yet fully understood.

There are some studies reporting that $T$. cruzi can interfere with the host cell cycle, although the mechanisms behind this process have not yet been fully described. The transcriptome revealed downregulation of cell cycle and cell division genes (Shigihara et al., 2008; Costales et al., 2009), though there was no difference in S-phase between uninfected cells and infected cells after $48 \mathrm{~h}$ of infection (Costales et al., 2009). Our recent findings suggest that infected cells are less likely to be in $\mathrm{S}$ phase as compared to control.

Several genes related to DNA metabolism are upregulated during early timepoints of infection $(3 \mathrm{~h}$ and $6 \mathrm{~h}$ post-infection), such as the DNA polymerases POLK and $P O L B$, DNA helicase RECQL, and DNA glycosylase $S M U G 1$, that are involved in various types of DNA repair, including mismatch repair, base excision repair, and direct repair (Costales et al., 2009). It was also reported that $T$. cruzi induces DNA breaks in cardiomyocytes during late stages of infection; the breaks are repaired when cells are treated with a free radical ion trap $(\mathrm{PBN})$. PAR levels were increased in T. cruzi infected cells (Ba et al., 2010). These results suggest that oxidative stress leads to BER pathway activation in the host cell during infection. The mechanisms behind genotoxicity in host cells are not yet fully understood and research efforts toward this end are underway.

There is some evidence that $T$. cruzi infection can induce not only host cell cycle arrest, but might also lead to senescence (Guimarães-Pinto et al., 2018). It was revealed that a senescence-associated secretory phenotype (SASP) characterized by the production of a specific set of cytokines and chemokines such as IL-6, TNF- $\alpha$, IL-1 $\beta$, and MCP-1 and also secretion of SA- $\beta$-galactose are higher in infected fibroblast cells when compared to non-infected cells. The authors observed that host cell nuclei presented a characteristic senescence-associated heterochromatin focus. In addition, they observed that antioxidants reduced SASP molecules in the host cell and inhibited parasite growth. Cellular senescence, by definition, impairs cell cycle progression, which could benefit amastigote multiplication in the host environment. These results suggest that parasite growth in fibroblasts leads to host cell senescence, which benefits $T$. cruzi reproduction in the host cell cytosol.

In cell culture after parasite growth, the host cell will eventually die, spreading parasites to the supernatant. How the parasite induces host cell death is controversial. It has been reported that $T$. cruzi can induce apoptosis in the host cell (Stahl et al., 2013). The authors observed activation of caspases 3/7, 8, and 9 in cardiomyocytes infected with $T$. cruzi when compared to control cells. In this model, STAT3 
activation was induced by infection. Therefore, the Janus Kinase (JAK) signal-STAT pathway could be responsible for apoptosis and cardiomyopathy. Conversely, it was reported that $T$. cruzi could prevent cardiac cells from undergoing apoptosis via activation of NF-kB and IL-1 (Petersen et al., 2006). How the parasite contributes to cell death and how the cell fate decision might spread neighboring cells is an important issue that needs to be further study.

\section{Concluding remarks}

As described above, DNA metabolism and responses to DNA damage in both the parasite and host vary depending on the parasite in question and its specific life form. In Chagas disease, success of the infection and associated pathological effects are influenced by both parasite and host factors. (Andrade et al., 1999; Andrade and Andrews, 2005; Albertti et al., 2010; Kayama and Takeda 2010; Henrique et al., 2016). Parasite-host interactions have been studied for a long time and seem to be important for both cell types (Caradonna and Burleigh, 2011; Caradonna et al., 2013). The findings that $T$. cruzi can alter the mitochondrial membrane potential and the oxidative burst within the host cell to their benefit gives a new perspective on the infection process. Investigation into how the parasite regulates both its own and the host cell cycle is also essential, as this information could lead to new insights into the understanding of parasite/host interactions. Reports of how T. cruzi can regulate host cell cycle arrest and/or cell death in cardiomyocytes and further understanding of how the parasite enters a dormant state can lead to a new understanding of the disease mechanisms.

\section{Acknowlegments}

This work was supported by funds of $\mathrm{CNPq}$, FAPEMIG, CAPES and FAPESP.

\section{Conflict of interest}

The authors declare that there is no conflict of interest that could be perceived as prejudicial to the impartiality of the reported research.

\section{Author contributions}

BMR, PTVF wrote the manuscript; BMR, CRM, PTVF conceptualized the work; BMR, PTVF, CRM reviewed the manuscript. All authors read and approved the final version.

\section{References}

Aguiar PHN, Furtado C, Repolês BM, Ribeiro GA, Mendes IC, Peloso EF, Gadelha FR, Macedo AM, Franco GR, Pena SDJ et al. (2013) Oxidative stress and DNA lesions: The role of 8-oxoguanine lesions in Trypanosoma cruzi cell viability. PLoS Negl Trop Dis 7:e2279.

Albertti LAG, Macedo AM, Chiari E, Andrews NW and Andrade LO (2010) Role of host lysosomal associated membrane protein (LAMP) in Trypanosoma cruzi invasion and intracellular development. Microbes Infect 12:784-789.

Alexeyev M, Shokolenko I, Wilson G and LeDoux S (2013) The maintenance of mitochondrial DNA integrity - critical analysis and update. Cold Spring Harb Perspect Biol 5:a012641-a012641.

Allinson SL, Dianova II and Dianov GL (2001) DNA polymerase $\beta$ is the major dRP lyase involved in repair of oxidative base lesions in DNA by mammalian cell extracts. EMBO J 20:6919-26.

Alvarez MN, Piacenza L, Irigoín F, Peluffo G and Radi R (2004) Macrophage-derived peroxynitrite diffusion and toxicity to Trypanosoma cruzi. Arch Biochem Biophys 432:222-32.

Alvarez MN, Peluffo G, Piacenza L and Radi R (2011) Intraphagosomal peroxynitrite as a macrophage-derived cytotoxin against internalized Trypanosoma cruzi: Consequences for oxidative killing and role of microbial peroxiredoxins in infectivity. J Biol Chem 286:6627-40.

Alvarez VE, Niemirowicz GT and Cazzulo JJ (2012) The peptidases of Trypanosoma cruzi: Digestive enzymes, virulence factors, and mediators of autophagy and programmed cell death. Biochim Biophys Acta 1824:195-206.

Alves CL, Repolês BM, Silva MS, Mendes IC, Marin PA, Aguiar PHN, Santos SS, Franco GR, Macedo AM, Pena SDJ et al. (2018) The recombinase Rad51 plays a key role in events of genetic exchange in Trypanosoma cruzi. Sci Rep 8:13335.

Anderson CT and Friedberg EC (1980) The presence of nuclear and mitochondrial uracil-DNA glycosylase in extracts of human KB cells. Nucleic Acids Res 8:875-88.

Andrade LO and Andrews NW (2005) The Trypanosoma cruzi host-cell interplay: Location, invasion, retention. Nat Rev Microbiol 3:819-823.

Andrade LO, Machado CRS, Chiari E, Pena SDJ and Macedo AM (1999) Differential tissue distribution of diverse clones of Trypanosoma cruzi in infected mice. Mol Biochem Parasitol 100:163-172.

Ba X, Gupta S, Davidson M and Garg NJ (2010) Trypanosoma cruzi induces the reactive oxygen species-PARP-1-RelA pathway for up-regulation of cytokine expression in cardiomyocytes. J Biol Chem 285:11596-606.

Bahia-Oliveira LM, Gomes JA, Cançado JR, Ferrari TC, Lemos EM, Luz ZM, Moreira MC, Gazzinelli G and Correa-Oliveira R (2000) Immunological and clinical evaluation of chagasic patients subjected to chemotherapy during the acute phase of Trypanosoma cruzi infection 14-30 years ago. J Infect Dis 182:634-8.

Barzilai A and Yamamoto KI (2004) DNA damage responses to oxidative stress. DNA Repair (Amst) 3:1109-15.

Berasain P, Carmona C, Frangione B, Cazzulo JJ and Goñi F (2003) Specific cleavage sites on human IgG subclasses by cruzipain, the major cysteine proteinase from Trypanosoma cruzi. Mol Biochem Parasitol 130:23-9.

Berra CM, Menck CFM and Di Mascio P (2006) Estresse oxidativo, lesões no genoma e processos de sinalização no controle do ciclo celular. Quim Nova 29:1340-44.

Boiteux S, Coste F and Castaing B (2017) Repair of 8-oxo-7,8dihydroguanine in prokaryotic and eukaryotic cells: Properties and biological roles of the Fpg and OGG1 DNA N-glycosylases. Free Radic Biol Med 107:179-201.

Boveris A and Stoppani AOM (1977) Hydrogen peroxide generation in Trypanosoma cruzi. Experientia 33:1306-1308. 
Boveris A, Sies H, Martino EE, Docampo R, Turrens JF and Stoppani AO (1980) Deficient metabolic utilization of hydrogen peroxide in Trypanosoma cruzi. Biochem J 188:643-648.

Cadet J, Douki T, Gasparutto D and Ravanat JL (2003) Oxidative damage to DNA: Formation, measurement and biochemical features. Mutat Res 531:5-23.

Cagney G, Alvaro D, Reid RJD, Thorpe PH, Rothstein R and Krogan NJ (2006) Functional genomics of the yeast DNAdamage response. Genome Biol 7:7-10.

Cançado JR (2002) Long term evaluation of etiological treatment of Chagas disease with benznidazole. Rev Inst Med Trop Sao Paulo 44:29-37.

Cantey PT, Stramer SL, Townsend RL, Kamel H, Ofafa K, Todd CW, Currier M, Hand S, Varnado W, Dotson E et al. (2012) The United States Trypanosoma cruzi Infection Study: Evidence for vector-borne transmission of the parasite that causes Chagas disease among United States blood donors. Transfusion 52:1922-1930.

Cardoni RL, Antunez MI, Morales C and Rodriguez Nantes I (1997) Release of reactive oxygen species by phagocytic cells in response to live parasites in mice infected with Trypanosoma cruzi. Am J Trop Med Hyg 56:329-334.

Caradonna KL and Burleigh BA (2011) Mechanisms of host cell invasion by Trypanosoma cruzi. Adv Parasitol 76:33-61.

Caradonna KL, Engel JC, Jacobi D, Lee CH and Burleigh BA (2013) Host metabolism regulates intracellular growth of Trypanosoma cruzi. Cell Host Microbe 13:108-17

Cerqueira PG, Passos-Silva DG, Vieira-da-Rocha JP, Mendes IC, Oliveira KA, Oliveira CFB, Vilela LFF, Nagem RAP, Cardoso J, Nardelli SC et al. (2017) Effect of ionizing radiation exposure on Trypanosoma cruzi ubiquitin-proteasome system. Mol Biochem Parasitol 212:55-67.

Cestari IS, Krarup A, Sim RB, Inal JM and Ramirez MI (2009) Role of early lectin pathway activation in the complementmediated killing of Trypanosoma cruzi. Mol Immunol 47:426-37.

Chagas C (1909) Nova tripanozomiaze humana: estudos sobre a morfolojia e o ciclo evolutivo do Schizotrypanum cruzi n. gen., n. sp., ajente etiolojico de nova entidade morbida do homem. Mem Inst Oswaldo Cruz 1:159-218.

Chelikani P, Fita I and Loewen PC (2004) Diversity of structures and properties among catalases. Cell Mol Life Sci 61:192208.

Costales JA, Daily JP and Burleigh BA (2009) Cytokine-dependent and-independent gene expression changes and cell cycle block revealed in Trypanosoma cruzi-infected host cells by comparative mRNA profiling. BMC Genomics 10:252.

David SS, Shea VLO and Kundu S (2010) Base excision repair of oxidative DNA damage. Nature 447:941-950.

DiRuggiero J and Robb FT (2004) Early evolution of DNA repair mechanisms. In: Pouplana LR (ed) The Genetic Code and the Origin of Life. Kluwer Academic / Plenum Publishers, New York, pp 169-182.

El-Sayed NM, Myler PJ, Bartholomeu DC, Nilsson D, Aggarwal G, Tran AN, Ghedin E, Worthey EA, Delcher AL, Blandin G et al. (2005) The genome sequence of Trypanosoma cruzi, etiologic agent of Chagas disease. Science 309:409-415.

Fairlamb AH and Cerami A (1992) Metabolism and functions of trypanothione in the kinetoplastida. Annu Rev Microbiol 46:695-729.
Fairlamb AH, Blackburn P, Ulrich P, Chait BT and Cerami A (1985) Trypanothione: A novel bis(glutathionyl)spermidine cofactor for glutathione reductase in trypanosomatids. Science 227:1485-1487.

Farez-Vidal ME (2001) Characterization of uracil-DNA glycosylase activity from Trypanosoma cruzi and its stimulation by AP endonuclease. Nucleic Acids Res 29:1549-55.

Freire ACG, Alves CL, Goes GR, Resende BC, Moretti NS, Nunes VS, Aguiar PHN, Tahara EB, Franco GR, Macedo AM et al. (2017) Catalase expression impairs oxidative stress-mediated signalling in Trypanosoma cruzi. Parasitology 144:1498-1510.

Friedberg EC (2008) A brief history of the DNA repair field. Cell Res 18:3-7.

Furtado C, Kunrath-Lima M, Rajão MA, Mendes IC, Moura MB, Campos PC, Macedo AM, Franco GR, Pena SDJ, Teixeira SMR et al. (2012) Functional characterization of 8-oxoguanine DNA glycosylase of Trypanosoma cruzi. PLoS One 7:e42484.

Garcia JBF, Rocha JPV, Costa-Silva HM, Alves CL, Machado CR and Cruz AK (2016) Leishmania major and Trypanosoma cruzi present distinct DNA damage responses. Mol Biochem Parasitol 207:23-32.

Geiger A, Bossard G, Sereno D, Pissarra J, Lemesre JL, Vincendeau P and Holzmuller P (2016) Escaping deleterious immune response in their hosts: Lessons from trypanosomatids. Front Immunol 7:1-21.

Genois MM, Paquet ER, Laffitte MCN, Maity R, Rodrigue A, Ouellette M and Masson JY (2014) DNA repair pathways in trypanosomatids: From DNA repair to drug resistance. Microbiol Mol Biol Rev 78:40-73.

Giorgi C, Baldassari F, Bononi A, Bonora M, De Marchi E, Marchi S, Missiroli S, Patergnani S, Rimessi A, Suski JM et al. (2012) Mitochondrial $\mathrm{Ca}^{2+}$ and apoptosis. Cell Calcium 52:36-43.

Giorgi EM and De Lederkremer RM (2011) Trans-sialidase and mucins of Trypanosoma cruzi: An important interplay for the parasite. Carbohydr Res 346:1389-1393.

Glover L, McCulloch R and Horn D (2008) Sequence homology and microhomology dominate chromosomal double-strand break repair in African trypanosomes. Nucleic Acids Res 36:2608-2618.

Goes GR, Rocha PS, Diniz ARS, Aguiar PHN, Machado CR and Vieira LQ (2016) Trypanosoma cruzi needs a signal provided by reactive oxygen species to infect macrophages. PLoS Negl Trop Dis 10:1-25.

Guimarães-Pinto K, Nascimento DO, Corrêa-Ferreira A, Morrot A, Freire-de-Lima CG, Lopes MF, DosReis GA and Filardy AA (2018) Trypanosoma cruzi infection induces cellular stress response and senescence-like phenotype in murine fibroblasts. Front Immunol 9:1569.

Gupta S, Bhatia V, Wen JJ, Wu Y, Huang MH and Garg NJ (2009) Trypanosoma cruzi infection disturbs mitochondrial membrane potential and ROS production rate in cardiomyocytes. Free Radic Biol Med 47:1414-1421.

Gupta S, Dhiman M, Wen JJ and Garg NJ (2011) ROS Signalling of inflammatory cytokines during Trypanosoma cruzi infection. Adv Parasitol 76:153-170.

Hakem R (2008) DNA-damage repair; the good, the bad, and the ugly. EMBO J 27:589-605. 
Harper JW and Elledge SJ (2007) The DNA damage response: Ten years after. Mol Cell 28:739-745.

Henrique PM, Marques T, Silva MV, Nascentes GAN, Oliveira $\mathrm{CF}$, Rodrigues $\mathrm{V}$, Gómez-Hernández $\mathrm{C}$, Norris KA, Ramirez LE and Meira WSF (2016) Correlation between the virulence of $T$. cruzi strains, complement regulatory protein expression levels, and the ability to elicit lytic antibody production. Exp Parasitol 170:66-72.

Hoeijmakers JHJ (2001) Genome maintenance mechanism for preventing cancer. Nature 411:366-374.

Horn D and McCulloch R (2010) Molecular mechanisms underlying the control of antigenic variation in African trypanosomes. Curr Opin Microbiol 13:700-705.

Hwang BJ, Shi G and Lu AL (2014) Mammalian MutY homolog (MYH or MUTYH) protects cells from oxidative DNA damage. DNA Repair (Amst) 13:10-21.

Imlay JA (2013) The molecular mechanisms and physiological consequences of oxidative stress: Lessons from a model bacterium. Nat Rev Microbiol 11:443-454.

Kanvah S, Joseph J, Schuster GB, Barnett RN, Cleveland CL and Landman UZI (2010) Oxidation of DNA: Damage to nucleobases. Acc Chem Res 43:280-87.

Kayama H and Takeda K (2010) The innate immune response to Trypanosoma cruzi infection. Microbes Infect 12:511-517.

Kazak L, Reyes A and Holt IJ (2012) Minimizing the damage: Repair pathways keep mitochondrial DNA intact. Nat Rev Mol Cell Biol 13:659-671.

Krauth-Siegel RL, Meiering SK and Schmidt H (2003) The parasite-specific trypanothione metabolism of trypanosoma and leishmania. Biol Chem 384:539-49.

Kroemer G, Galluzzi L and Brenner C (2007) Mitochondrial membrane Permeabilization in cell death. Physiol Rev 87:99-163.

Kuipers GK, Slotman BJ, Poldervaart HA, Reitsma-Wijker CA and Lafleur MVM (2000) The influence of combined Fpgand MutY-deficiency on the spontaneous and $\gamma$-radiationinduced mutation spectrum in the lacZ $\alpha$ gene of M13mp10. Mutat Res 461:189-195.

Kunrath-Lima M, Repolês BM, Alves CL, Furtado C, Rajão MA, Macedo AM, Franco GR, Pena SDJ, Valenzuela L, Wisnovsky S et al. (2017) Characterization of Trypanosoma cruzi MutY DNA glycosylase ortholog and its role in oxidative stress response. Infect Genet Evol 55:332-342.

Laranja FS, Dias E, Nóbrega G and Miranda A (1956) Chagas' Ddsease: A clinical, epidemiologic, and pathologic study. Circulation 14:1035-1060.

Lopes DO, Schamber-Reis BLF, Regis-da-Silva CG, Rajão MA, DaRocha WD, Macedo AM, Franco GR, Nardelli SC, Schenkman S, Hoffmann JS et al. (2008) Biochemical studies with DNA polymerase $\beta$ and DNA polymerase $\beta$-PAK of Trypanosoma cruzi suggest the involvement of these proteins in mitochondrial DNA maintenance. DNA Repair (Amst) 7:1882-1892.

Lord CJ and Ashworth A (2012) The DNA damage response and cancer therapy. Nature 481:287-294.

Machado-Silva A, Cerqueira PG, Grazielle-Silva V, Gadelha FR, Peloso EF, Teixeira SMR and Machado CR (2016) How Trypanosoma cruzi deals with oxidative stress: Antioxidant defence and DNA repair pathways. Mutat Res 767:8-22.

Mahon KP, Potocky TB, Blair D, Roy MD, Stewart KM, Chiles TC and Kelley SO (2007) Deconvolution of the cellular oxi- dative stress response with organelle-specific peptide conjugates. Chem Biol 14:923-930.

Manchekar M, Scissum-Gunn K, Song D, Khazi F, McLean SL and Nielsen BL (2006) DNA recombination activity in soybean mitochondria. J Mol Biol 356:288-99.

Marnett LJ and Plastaras JP (2001) Endogenous DNA damage and mutation. Trends Genet 17:214-221.

Martinez A, Prolo C, Estrada D, Rios N, Piñeyro D, Robello C, Radi R and Piacenza L (2018) Cytosolic Fe-superoxide dismutase protects Trypanosoma cruzi from macrophagederived superoxide radical increasing pathogen virulence in vivo. Free Radic Biol Med 20:S93.

Mason PA, Matheson EC, Hall AG and Lightowlers RN (2003) Mismatch repair activity in mammalian mitochondria. Nucleic Acids Res 31:1052-1058.

Mateo H, Marín C, Pérez-Cordón G and Sánchez-Moreno M (2008) Purification and biochemical characterization of four iron superoxide dismutases in Trypanosoma cruzi. Mem Inst Oswaldo Cruz 103:271-276.

McCulloch R and Barry JD (1999) A role for RAD51 and homologous recombination in Trypanosoma brucei antigenic variation. Genes Dev 13:2875-2888.

Meadows KL, Song B and Doetsch PW (2003) Characterization of AP lyase activities of Saccharomyces cerevisiae Ntg1p and Ntg2p: Implications for biological function. Nucleic Acids Res 31:5560-5567.

Melis JPM, van Steeg H and Luijten M (2013) Oxidative DNA damage and nucleotide excision repair. Antioxid Redox Signal 18:2409-2419.

Meziane-Cherif D, Aumercier M, Kora I, Sergheraert C, Tartar A, Dubremetz JF and Ouaissi MA (1994) Trypanosoma cruzi: Immunolocalization of trypanothione reductase. Exp Parasitol 79:536-41.

Michaels ML and Miller JH (1992) The GO system protects organisms from the mutagenic effect of the spontaneous lesion 8-hydroxyguanine (7,8-dihydro-8-oxoguanine). J Bacteriol 174:6321-6325.

Mileshina D, Koulintchenko M, Konstantinov Y and Dietrich A (2011) Transfection of plant mitochondria and in organello gene integration. Nucleic Acids Res 39:e115.

Minczuk M, He J, Duch AM, Ettema TJ, Chlebowski A, Dzionek K, Nijtmans LGJ, Huynen MA and Holt IJ (2011) TEFM (c17orf42) is necessary for transcription of human mtDNA. Nucleic Acids Res 39:4284-99.

Morel F, Renoux M, Lachaume P and Alziari S (2008) Bleomycin-induced double-strand breaks in mitochondrial DNA of Drosophila cells are repaired. Mutat Res 637:111-117.

Moreno SN (2004) Cytosolic-free calcium elevation in Trypanosoma cruzi is required for cell invasion. J Exp Med 180:1535-1540.

Müller S, Liebau E, Walter RD and Krauth-Siegel RL (2003) Thiol-based redox metabolism of protozoan parasites. Trends Parasitol 19:320-328.

Muñoz-Fernández MA, Fernández MA and Fresno M (1992) Activation of human macrophages for the killing of intracellular Trypanosoma cruzi by TNF- $\alpha$ and IFN- $\gamma$ through a nitric oxide-dependent mechanism. Immunol Lett 33:35-40.

Nash HM, Bruner SD, Schärer OD, Kawate T, Addona TA, Spooner E, Lane WS and Verdine GL (1996) Cloning of a yeast 8-oxoguanine DNA glycosylase reveals the existence 
of a base-excision DNA-repair protein superfamily. Curr Biol 6:968-980.

Nathan C and Shiloh MU (2002) Reactive oxygen and nitrogen intermediates in the relationship between mammalian hosts and microbial pathogens. Proc Natl Acad Sci U S A 97:8841-8848

Nemzow L, Lubin A, Zhang L and Gong F (2015) XPC: Going where no DNA damage sensor has gone before. DNA Repair (Amst) 36:19-27.

Norris KA, Bradt B, Cooper NR and So M (1991) Characterization of a Trypanosoma cruzi $\mathrm{C} 3$ binding protein with functional and genetic similarities to the human complement regulatory protein, decay-accelerating factor. J Immunol 147:2270-2277.

Oladiran A and Belosevic M (2012) Immune evasion strategies of trypanosomes: A review. J Parasitol 98:284-292.

Paiva CN and Bozza MT (2014) Are reactive oxygen species always detrimental to pathogens? Antioxid Redox Signal 20:1000-1037.

Paiva CN, Feijó DF, Dutra FF, Carneiro VC, Freitas GB, Alves LS, Mesquita J, Fortes GB, Figueiredo RT, Souza HSP et al. (2012) Oxidative stress fuels Trypanosoma cruzi infection in mice. J Clin Invest 122:2531-2542.

Paiva CN, Medei E and Bozza MT (2018) ROS and Trypanosoma cruzi: Fuel to infection, poison to the heart. PLoS Pathog 14:e1006928.

Pascucci B, D'Errico M, Dogliotti E, Giovannini S and Parlanti E (2011) Role of nucleotide excision repair proteins in oxidative DNA damage repair: An updating. Biochem 76:4-15.

Passos-Silva DG, Rajão MA, Nascimento De Aguiar PH, VieiraDa-Rocha JP, Machado CR and Furtado C (2010) Overview of DNA repair in Trypanosoma cruzi, Trypanosoma brucei, and Leishmania major. J Nucleic Acids 2010:840768.

Peña-Diaz J, Akbari M, Sundheim O, Esther Farez-Vidal M, Andersen S, Sneve R, Gonzalez-Pacanowska D, Krokan HE and Slupphaug G (2004) Trypanosoma cruzi contains a single detectable uracil-DNA glycosylase and repairs uracil exclusively via short patch base excision repair. J Mol Biol 342:787-799.

Pereira PCM and Navarro EC (2013) Challenges and perspectives of Chagas disease: A review. J Venom Anim Toxins Incl Trop Dis 19:1-8.

Pérez-Molina JA and Molina I (2018) Chagas disease. Lancet 391:82-94.

Petersen CA, Krumholz KA, Carmen J, Sinai AP and Burleigh BA (2006) Trypanosoma cruzi infection and nuclear factor kappa B activation prevent apoptosis in cardiac cells. Infect Immun 74:1580-1587.

Pettepher CC, LeDoux SP, Bohr VA and Wilson GL (1991) Repair of alkali-labile sites within the mitochondrial DNA of RINr 38 cells after exposure to the nitrosourea streptozotocin. J Biol Chem 266:3113-3117.

Piacenza L, Irigoín F, Alvarez MN, Peluffo G, Taylor MC, Kelly JM, Wilkinson SR and Radi R (2007) Mitochondrial superoxide radicals mediate programmed cell death in Trypanosoma cruzi?: Cytoprotective action of mitochondrial iron superoxide dismutase overexpression. Biochem J 403:323334.

Piacenza L, Alvarez MN, Peluffo G and Radi R (2009a) Fighting the oxidative assault: the Trypanosoma cruzi journey to infection. Curr Opin Microbiol 12:415-421.
Piacenza L, Zago MP, Peluffo G, Alvarez MN, Basombrio MA and Radi R (2009b) Enzymes of the antioxidant network as novel determiners of Trypanosoma cruzi virulence. Int J Parasitol 39:1455-1464.

Piacenza L, Trujillo M and Radi R (2019) Reactive species and pathogen antioxidant networks during phagocytosis. J Exp Med 216:501-516.

Pinto AYN, Valente SA, Valente VC, Ferreira Junior AG and Coura JR (2008) Acute phase of Chagas disease in the Brazilian Amazon region: Study of 233 cases from Pará, Amapá and Maranhão observed between 1988 and 2005. Rev Soc Bras Med Trop 41:602-614.

Ponce I, Aldunate C, Valenzuela L, Sepúlveda S, Garrido G, Kemmerling U, Cabrera G and Galanti N (2017) A flap endonuclease (TcFEN1) is involved in Trypanosoma cruzi cell proliferation, DNA repair, and parasite survival. J Cell Biochem 118:1722-1732.

Prata A (2001) Clinical and epidemiological aspects of Chagas disease. Lancet Infect Dis 1:92-100.

Radicella JP, Dherin C, Chantal D, Fox MS and Boiteux S (1997) Cloning and characterization of hOGG1, a human homolog of the OGG1 gene of Saccharomyces cerevisiae. Proc Natl Acad Sci U S A 94:8010-8015.

Rajão MA, Passos-Silva DG, DaRocha WD, Franco GR, Macedo AM, Pena SDJ, Teixeira SM and Machado CR (2009) DNA polymerase kappa from Trypanosoma cruzi localizes to the mitochondria, bypasses 8-oxoguanine lesions and performs DNA synthesis in a recombination intermediate. Mol Microbiol 71:185-197.

Rajão MA, Furtado C, Alves CL, Passos-Silva DG, De Moura MB, Schamber-Reis BL, Kunrath-Lima M, Zuma AA, Vieira-da-Rocha JP, Garcia JBF et al. (2014) Unveiling Benznidazole's mechanism of action through overexpression of DNA repair proteins in Trypanosoma cruzi. Environ Mol Mutagen 55:309-321.

Ramírez G, Valck C, Molina MC, Ribeiro CH, López N, Sánchez G, Ferreira VP, Billetta R, Aguilar L, Maldonado I et al. (2011) Trypanosoma cruzi calreticulin: A novel virulence factor that binds complement $\mathrm{C} 1$ on the parasite surface and promotes infectivity. Immunobiology 216:265-273.

Rassi A, Rassi A and Marin-Neto JA (2010) Chagas disease. Lancet 375:1388-1402.

Regis-da-Silva CG, Freitas JM, Passos-Silva DG, Furtado C, Augusto-Pinto L, Pereira MT, DaRocha WD, Franco GR, Macedo AM, Hoffmann JS et al. (2006) Characterization of the Trypanosoma cruzi Rad51 gene and its role in recombination events associated with the parasite resistance to ionizing radiation. Mol Biochem Parasitol 149:191-200.

Rigalli JP, Perdomo VG, Ciriaci N, Francés DEA, Ronco MT, Bataille AM, Ghanem CI, Ruiz ML, Manautou JE and Catania VA (2016) The antitripanocide benznidazole promotes adaptive response to oxidative injury: Involvement of the nuclear factor-erythroid 2-related factor-2 (Nrf2) and multidrug resistance associated protein 2 (MRP2). Toxicol Appl Pharmacol 304:90-98.

Sánchez-Valdéz FJ, Padilla A, Wang W, Orr D and Tarleton RL (2018) Spontaneous dormancy protects Trypanosoma cruzi during extended drug exposure. eLife 7:34039

Schamber-Reis BLF, Nardelli S, Régis-Silva CG, Campos PC, Cerqueira PG, Lima SA, Franco GR, Macedo AM, Pena SDJ, Cazaux C et al. (2012) DNA polymerase beta from 
Trypanosoma cruzi is involved in kinetoplast DNA replication and repair of oxidative lesions. Mol Biochem Parasitol 183:122-131.

Sepúlveda S, Valenzuela L, Ponce I, Sierra S, Bahamondes P, Ramirez S, Rojas V, Kemmerling U, Galanti N and Cabrera G (2014) Expression, functionality, and localization of apurinic/apyrimidinic endonucleases in replicative and non-replicative forms of Trypanosoma cruzi. J Cell Biochem 115:397-409.

Shigihara T, Hashimoto M, Shindo N and Aoki T (2008) Transcriptome profile of Trypanosoma cruzi-infected cells: Simultaneous up- and down-regulation of proliferation inhibitors and promoters. Parasitol Res 102:715-722.

Shokolenko I, LeDoux S, Wilson G and Alexeyev M(2011) Mitochondrial DNA damage, repair, degradation and experimental approaches to studying these phenomena. In: Storici $\mathrm{F}$ (ed) DNA Repair - Pathways to Fixing DNA Damage Errors. IntechOpen, London, pp 339-355.

Silva DGP, Santos SS, Nardelli SC, Mendes IC, Freire ACG, Repolês BM, Resende BC, Costa-Silva HM, Silva VS, Oliveira KA et al. (2018) The in vivo and in vitro roles of Trypanosoma cruzi Rad51 in the repair of DNA double strand breaks and oxidative lesions. PLoS Negl Trop Dis 12:e006875.

Slupska MM, Baikalov C, Luther WM, Chiang JH, Wei YF and Miller JH (1996) Cloning and sequencing a human homolog (hMYH) of the Escherichia coli mutY gene whose function is required for the repair of oxidative DNA damage. J Bacteriol 178:3885-3892.

Souza FSP, Rampazzo RCP, Manhaes L, Soares MJ, Cavalcanti DP, Krieger MA, Goldenberg S and Fragoso SP (2010) Knockout of the gene encoding the kinetoplast-associated protein 3 (KAP3) in Trypanosoma cruzi: Effect on kinetoplast organization, cell proliferation and differentiation. Mol Biochem Parasitol 172:90-98.

Souza-Pinto NC, Mason PA, Hashiguchi K, Weissman L, Tian J, Guay D, Lebel M, Stevnsner TV, Rasmussen LJ and Bohr VA (2009) Novel DNA mismatch-repair activity involving YB-1 in human mitochondria. DNA Repair (Amst) 8:704-719.

Stahl P, Ruppert V, Meyer T, Schmidt J, Campos MA, Gazzinelli RT, Maisch B, Schwarz RT and Debierre-Grockiego F (2013) Trypomastigotes and amastigotes of Trypanosoma cruzi induce apoptosis and STAT3 activation in cardiomyocytes in vitro. Apoptosis 18:653-663.

Tambourgi DV, Kipnis TL, Silva WD, Joiner KA, Sher A, Heath S, Hall BF and Ogden GB (1993) A partial cDNA clone of trypomastigote decay-accelerating factor (T-DAF), a developmentally regulated complement inhibitor of Trypanosoma cruzi, has genetic and functional similarities to the hu- man complement inhibitor DAF. Infect Immun 61:3656-3663.

Tardieux I (2004) Role in host cell invasion of Trypanosoma cruzi-induced cytosolic-free $\mathrm{Ca} 2+$ transients. J Exp Med 179:1017-1022.

Taylor JE and Rudenko G (2006) Switching trypanosome coats: What's in the wardrobe? Trends Genet 22:614-620.

Teixeira ARL, Nitz N, Guimaro MC, Gomes C and Santos-Buch CA (2006) Chagas disease. Postgrad Med J 82:788-798.

Thyagarajan B, Padua RA and Campbell C (1996) Mammalian mitochondria possess homologous DNA recombination activity. J Biol Chem 271:27536-27543.

Trindade S, Rijo-Ferreira F, Carvalho T, Pinto-Neves D, Guegan F, Aresta-Branco F, Bento F, Young SA, Pinto A, Van Den Abbeele J et al. (2016) Trypanosoma brucei parasites occupy and functionally adapt to the adipose tissue in mice. Cell Host Microbe 19:837-848.

Tubbs A and Nussenzweig A (2017) Endogenous DNA damage as a source of genomic instability in cancer. Cell 168:644656.

van Loon B, Markkanen E and Hübscher U (2010) Oxygen as a friend and enemy: How to combat the mutational potential of 8-oxo-guanine. DNA Repair (Amst) 9:604-616.

Wallace SS (2014) Base excision repair: A critical player in many games. DNA Repair (Amst) 19:14-26.

Weatherly DB, Peng D and Tarleton RL (2016) Recombination-driven generation of the largest pathogen repository of antigen variants in the protozoan Trypanosoma cruzi. BMC Genomics 17:729.

Webster KA (2012) Mitochondrial membrane permeabilization and cell death during myocardial infarction: Roles of calcium and reactive oxygen species. Future Cardiol 8:863884.

Wilkinson SR, Meyer DJ, Taylor MC, Bromley EV, Miles MA and Kelly JM (2002) The Trypanosoma cruzi enzyme TcGPXI is a glycosomal peroxidase and can be linked to trypanothione reduction by glutathione or tryparedoxin. J Biol Chem 277:17062-17071.

\section{Internet Resources}

Centers for Disease and Control Prevention (2018) Parasites - Leishmaniasis, https://www.cdc.gov/parasites/leishmaniasis/biology.html (accessed 14 December 2018).

Associate Editor: Carlos F. M. Menck

License information: This is an open-access article distributed under the terms of the Creative Commons Attribution License (type CC-BY), which permits unrestricted use, distribution and reproduction in any medium, provided the original article is properly cited. 